\title{
Vigencia de la teología latinoamericana de la liberación: a cinco décadas de su origen*
}

\author{
Jorge Costadoat ${ }^{\mathrm{a}}$
}

Pontificia Universidad Católica de Chile

http://orcid.org/0000-0002-3364-9899

RECIBIDO: 15-01-20. ACEPTADO: 07-04-20

Resumen: En este artículo se da cuenta de aquello que perdura como novedoso de la teología latinoamericana de la liberación a cinco décadas de sus comienzos. El texto sitúa a esta teología en continuidad y como expresión de la recepción latinoamericana del Concilio Vaticano II. Los teólogos de la liberación han convenido en pensar que en Medellín (1968) comenzó una apropiación creativa del Concilio, que consistió, en pocas palabras, en una opción por los pobres. El caso es que, si en los comienzos esta teología puso el énfasis en la necesidad de hacer cambios sociales y económicos estructurales en sociedades injustas, con el correr del tiempo ha descubierto la importancia de los pobres como sujetos de su reflexión y liberación. Ha sido muy significativo, en este sentido, descubrir el enorme valor de la lectura popular de la Biblia realizada en las comunidades eclesiales de base. Este artículo revisa, por lo mismo, el método de la teología de la liberación. Con el correr de los años se ha hecho necesario actualizar el planteamiento de Gustavo Gutiérrez para precisar lo esencial e incorporar el aporte, por ejemplo, de la teología feminista y de la teología india. Estas, bien distintas en cuanto a sus sujetos y temáticas, comparten sin embargo el ser teologías inductivas de colectivos que descubren su opresión. En una última sección, el artículo describe la que sería una novedad mayor, la concepción de la revelación. Varios teólogos no solo acogen el círculo hermenéutico de las teologías contextuales, sino que postulan que Dios continúa revelándose en el presente histórico con una Palabra nueva, la que se hace oír en el clamor de los pobres por su liberación. Palabras clave: Teología de la liberación; método; América Latina; recepción del Concilio Vaticano II; revelación.

*Artículo de investigación.

a Autor de correspondencia. Correo electrónico: jcostado@uc.cl 


\section{Validity of Latin American Liberation Theology:}

five decades after it's beginning

AвSTRACт: This article reveals what endures as a novelty of the Latin American Liberation Theology five decades after its beginning. The text places this theology in continuium with the expression of the Latin American reception of Vatican II. Liberation theologians agree that in Medellín (1968) a creative appropriation of the Council began, specifically, in an option for the poor. The fact is that, if at the beginning this theology emphasized on the need to make structural social and economic changes in unjust societies, over time it has discovered the importance of the poor as subjects of its reflection and liberation. It has been very significant, in this sense, to discover the enormous value of the popular reading of the Bible carried out in the Base Ecclesial Communities. Therefore, this article reviews the Theology of Liberation method. Over the years it has become necessary to update Gustavo Gutierrez's approach in order to specify the essence and incorporate the contribution, for example, of Feminist Theology and Indian Theology. These, quite different in terms of their subjects and themes, however, share being inductive theologies of groups that discover their oppression. In a final section, the article describes what would be a major novelty, the concept of revelation. Several theologians not only embrace the hermeneutical circle of contextual theologies, but postulate that God continues to reveal himself in the historical present with a new Word, which is heard in the outcry of the poor for their liberation.

Key words: Liberation Theology; Method; Latin America; Second Vatican Council's Reception; Revelation.

\section{CÓMO CITAR:}

Costadoat, Jorge. "Vigencia de la teología latinoamericana de la liberación: a cinco décadas de su origen”. Theologica Xaveriana (2021): 1-26. https://doi.org/10.11144/ javeriana.tx71.vtllcdo

\section{Reconocimiento}

Este texto se enmarca en el proyecto de investigación Fondecyt N. ${ }^{\circ} 1190556$. Se titula "El estatuto teológico de la Palabra de Dios en los acontecimientos históricos actuales. Articulación entre principios teológicos y datos empíricos”, se desarrolla en la Universidad Alberto Hurtado, con fecha de inicio en 2019 y de finalización en 2021. 


\section{Introducción}

Es difícil datar los comienzos de la teología de la liberación o teología latinoamericana de la liberación. En este artículo se usará esta última denominación pues, con el correr de los años, la primera teología desarrollada en el posconcilio en América Latina que puso el énfasis en la liberación de los oprimidos ha seguido más de un itinerario, se ha abierto a las dimensiones socioculturales de la realidad de los pobres y, en todo caso, ha profundizado sus convicciones principales y se ha vuelto autocrítica ${ }^{1}$.

No es fácil fechar el origen de la teología latinoamericana de la liberación. Ella, además, está estrechamente vinculada a un movimiento eclesial desencadenado por el Concilio Vaticano II y a acontecimientos que han agitado a los pueblos latinoamericanos y al modo de pensar su misma historia. No obstante, es conveniente hablar de cinco décadas porque estos comienzos estuvieron asociados a la II Conferencia General del Episcopado Latinoamericano de Medellín (1968).

Volver sobre el tema es importante. Sobre la teología latinoamericana de la liberación se ha escrito mucho. Pero no está de más insistir en su estudio, pues lo publicado en estos cincuenta años no tiene comparación alguna con la creación teológica nativa en los quinientos años transcurridos desde la Conquista y descubrimiento de América. Esta parece ser la primera y, en cierto sentido, la única teología propiamente latinoamericana ${ }^{2}$. En 1960, Marcos Mc Grath, entonces decano de la Facultad de Teología de la Universidad Católica de Chile, sostenía:

Consúltese cualquier libro de nota publicado en Europa o Norteamérica en filosofía o teología. búsquese la bibliografía. Entre centenares de títulos citados es más que probable que no se encuentre siquiera una obra escrita y publicada en Latinoamérica. No es que nos desconozcan; es que no hay casi nada nuestro que merezca citarse. ${ }^{3}$

No debe esperarse de este artículo dar cuenta completa de la vigencia de la teología latinoamericana de la liberación. Su intento, más bien, es mostrar lo que se ha ido decantando con visos de perdurabilidad.

Aquí se reitera que la teología latinoamericana de la liberación constituye una recepción genuina del Concilio Vaticano II; se describe el lugar eclesiológico más rico de su elaboración: las comunidades eclesiales de base; se ofrece una recomprensión

\footnotetext{
${ }^{1}$ En algunas ocasiones se mantendrá el uso del nombre teología de la liberación para hacer referencia a la teología de los primeros años.

${ }^{2}$ Esta afirmación es discutible. Se ha procurado defenderla en Costadoat, "Identidad de la teología de la liberación y la teología latinoamericana”, 19-40.

${ }^{3}$ Mc Grath, "La misión de la teología en Latinoamérica”, 15.
} 
de su método y se da cuenta de dos ramificaciones importantes: la teología india y la teología feminista; por último se señala la que sería una innovación mayor en el concepto de revelación, a saber, la de reconocer que Dios se revela en los acontecimientos históricos actuales, independientemente de la Escritura y la tradición, criterios por excelencia para interpretarla.

\section{La recepción latinoamericana del Concilio}

El Concilio Vaticano II tuvo enorme impacto en la Iglesia latinoamericana. Gaudium et spes ha tenido especial importancia por el modo de ser Iglesia que desencadenó y por ofrecer a los latinoamericanos un método teológico inductivo que ha permitido a la Iglesia del continente atender y discernir sus propios signos de los tiempos ${ }^{4} \mathrm{y}$, por ende, acceder a una mayor adultez 5 .

Es así como la convergencia en Medellín de la jerarquía eclesiástica y los teólogos de la naciente teología latinoamericana de la liberación deben considerarse un hito de una Iglesia en camino de su autoconciencia y de la autonomía que distingue a los mayores de edad obligados a responder ante nuevas circunstancias, por sí mismos y ante sí mismos con creatividad. En palabras de Gustavo Gutiérrez:

La teología de la liberación es una de las expresiones de la adultez que comienza a alcanzar la sociedad latinoamericana y la Iglesia presente en ella en las últimas décadas. Medellín tomó acta de esta edad mayor y ello contribuyó poderosamente a su significación y alcance históricos. ${ }^{6}$

La recepción del Concilio en América Latina fue "selectiva y creativa”. La II Conferencia General del Episcopado en Medellín hizo suyos los principales mandatos del Vaticano II, aun cuando las preocupaciones del Concilio fueran prioritariamente dialogar con la Modernidad y desarrollar el ecumenismo ${ }^{8}$. En Medellín -en pocos díaslos obispos elucidaron cuáles eran las preocupaciones latinoamericanas y, en vista a

\footnotetext{
${ }^{4}$ Codina, "Las iglesias del continente 50 años después del Vaticano II", 84.

${ }^{5}$ Luciani, "Medellín Fifty Years Later: From Development to Liberation”, 589.

${ }^{6}$ Gutiérrez, Teología de la liberación. Perspectivas, 31.

${ }^{7}$ Galilea, "Ejemplo de recepción selectiva y creativa del Concilio: América Latina en las conferencias de Medellín y Puebla", 86-101.

${ }^{8}$ Los teólogos latinoamericanos han lamentado que la moción de Juan XXIII y del cardenal Lercaro de una "Iglesia de los pobres" no hubiera cobrado el interés que merecía (ver a Sobrino, “La Iglesia de los pobres' no prosperó en el Vaticano II. Promovida en Medellín, historizó elementos esenciales en el Concilio", 24-33; y a De Aquino Júnior, "Iglesia de los pobres. Del Vaticano II a Medellín y nuestros días", 277-298).
} 
estos desafíos, elaboraron varias pastorales, muchas de ellas válidas hasta el presente. Obispos y teólogos trabajaron juntos en la redacción de los 16 documentos.

En virtud del ejercicio de discernir los propios signos de los tiempos, los obispos latinoamericanos llegaron a concluir en los años sucesivos, por ejemplo, que la pobreza es un pecado social y que Dios opta por los pobres. "La opción preferencial por los pobres", anticipada en Medellín (1968), proclamada en Puebla (1979), y ratificada en Santo Domingo (1992) y en Aparecida (2007) -no es exagerado decirlo- es el nombre de la recepción latinoamericana del Vaticano II'.

Esta recepción, sin embargo, fue frenada tempranamente por la reacción tradicionalista, asustada y preocupada, tanto por cambios tocantes a las formas de la religiosidad como por la orientación social que la Iglesia asumía. La alianza de los sectores eclesiásticos preconciliares, los nuevos movimientos laicales conservadores, las elites ricas del continente e incluso el gobierno de EE.UU..$^{10}$, en un par de décadas, fueron arrolladores.

La Iglesia de Medellín, deseosa de ser solidaria con los pobres, tuvo prontamente dificultades para realizar su proyecto. El cardenal Alfonso López Trujillo, presidente del Consejo Episcopal Latinoamericano, Celam, desde 1972, combatió la renovación comenzada con la II Conferencia. Lo mismo hizo el entonces cardenal Ratzinger, prefecto de la Congregación para la Doctrina de la Fe, quien se encargó de poner coto a la teología de la liberación. Con su Instrucción sobre algunos aspectos de la 'Teología de la liberación"” (1984) salió al paso de una teología distinta de la suya ${ }^{11}$.

Con medidas disciplinares, por otra parte, inició un proceso de hostigamientos, sanciones y condenas a teólogos y teólogas latinoamericanas. Los casos más conocidos han sido los de Gustavo Gutiérrez, Leonardo Boff, Ivone Gebara y, durante el pontificado de Benedicto XVI, el de Jon Sobrino. También debe recordarse la censura del Celam al Proyecto Palabra-Vida elaborado por la Conferencia Latinoamericana de Religiosos y Religiosas, CLAR, con reflexiones para religiosos

\footnotetext{
9 Ernesto Valiente piensa que la opción preferencial por los pobres "provides a hermeneutical perspective that guides the Church's pastoral directives and priorities, orients Christian praxis toward a more authentic following of Jesus Christ, and should be incorporated into the Church's theological reflection. Thus understood, the preferential option for the poor is the most important contribution of the Latin American church to the universal church and is a necessary step in the fulfilling of John XXIII's wish for the Second Vatican Council: that it would lead us to become 'a church of the poor"' (Valiente, "The Reception of the Vatican II in Latin America", 823).

${ }^{10}$ Dussel, “Teología de la liberación y marxismo", Vol. 1, 115-144.

${ }^{11}$ Segundo, Teología de la liberación. Respuesta al cardenal Ratzinger, 27. Dos años después, el cardenal Ratzinger publicó un nuevo documento sobre el tema, este más benévolo, titulado Instrucción sobre libertad cristiana y liberación (Ciudad del Vaticano: 1986).
} 
en el quinquenio 1988-1993. Durante este periodo, las religiosas, especialmente las insertas en barrios populares, debieron afrontar los maltratos de parte de un nuevo clero sumamente autoritario.

Así mismo, en el frente externo, el movimiento generado por la recepción del Concilio en América Latina produjo mártires. El caso emblemático fue el de El Salvador, donde la resistencia a la "Iglesia de los pobres" causó la persecución y el asesinato de miles de cristianos miembros de comunidades. Entre estos se recuerda a las norteamericanas Dorothy Kazel, ursulina, Jean Donovan, laica, y a las hermanas Ita Ford y Maura Clarke, de Maryknoll. También son de recordar los seis jesuitas de la Universidad Centro Americana, UCA, de El Salvador, asesinados en ese mismo centro de educación superior. El crimen de Ignacio Ellacuría da testimonio de una teología martirial. Y "San Romero de América”, como ha sido llamado en el continente monseñor Óscar Arnulfo Romero aun antes de su canonización, representa a estas y a tantas otras víctimas laicos y laicas de las comunidades cristianas.

Después de Medellín, la Conferencia de Puebla, inaugurada por Juan Pablo II, experimentó ya fuertes tensiones. No fue fácil volver a utilizar el método ver-juzgar-actuar, útil para escrutar los signos de los tiempos e impulsar cambios pastorales, tal como hizo Medellín. Tampoco habría debido ser fácil adoptarlo, si se tiene en cuenta que el método inductivo de la misma Gaudium et spes fue foco, durante el Concilio, de fuertes discusiones entre franceses y alemanes. Ni Ratzinger ni Rahner entendían bien su novedad teológica ${ }^{12}$.

Bien puede decirse que en Puebla hubo un "empate" entre conservadores y progresistas. Estos últimos, sin embargo, sacaron mejor partido de la novedad pastoral principiada en la conferencia anterior. En Santo Domingo, en cambio, la curia romana, en particular los cardenales Sodano y Medina, intervinieron la Conferencia al punto de poner en peligro la publicación del documento final.

También en Aparecida, varios años después, volvió a levantarse la preocupación por el método ver-juzgar-actuar. Es sintomático que, a propósito de este método, su definición haya vuelto de Roma cambiada. La última redacción no se entiende ${ }^{13}$. El texto definitivo de Aparecida volvió de Roma con correcciones al texto de los obispos latinoamericanos tales como la mencionada y, otra muy importante, la atingente a las Comunidades eclesiales de base.

\footnotetext{
${ }^{12}$ Schickendantz, "Una elipse con dos focos. Hacia un nuevo método teológico a partir de Gaudium et spes”, 78-79; Schickendantz, “¿Una transformación metodológica inadvertida? La novedad introducida por Gaudium et spes en los escritos de Joseph Ratzinger”, 9-37.

${ }^{13}$ Véase Celam, "Aparecida" 19.
} 
Si bien Aparecida concitó un acuerdo entre los congregados, y no pocos teólogos han sabido valorar varios de sus textos, solo con la llegada de Jorge Bergoglio al pontificado la Iglesia latinoamericana parece haber recuperado la senda de Medellín. En especial con Evangelii gaudium, Laudato si'y los discursos a los encuentros mundiales con los movimientos populares ${ }^{14}$, además de una infinidad de gestos simbólicos, Francisco, en poco tiempo, recuperó la confianza de los sectores progresistas de la Iglesia latinoamericana incluidos los teólogos de la liberación. No puede decirse lo mismo del impacto del Papa entre los obispos. Estos, hasta ahora, no muestran especial entusiasmo por el "papa de los pobres".

\section{Las comunidades eclesiales de base y la lectura popular de la Biblia}

Mención aparte merece la recepción de Dei Verbum. Quizás la lectura eclesial de la Biblia en el seno de las comunidades eclesiales de base sea la mejor recepción latinoamericana del Concilio, no tanto por la extensión de la experiencia, cuanto por su densidad eclesial y teológica. Vistas las cosas a la distancia, creo que este es el locus epistemológico emblemático de la teología latinoamericana de la liberación.

Si en los años 70 esta teología puso su acento en la lucha contra las estructuras injustas, con el correr del tiempo valoró aún más la lucha de los pobres por una vida digna; esta, a la vez, se comprendió a partir de la lectura de la Palabra de Dios (y la Palabra de Dios, al tiempo, fue comprendida a partir de la vida ${ }^{15}$. El ícono de la teología latinoamericana de la liberación es gente pobre con la Biblia en sus manos ${ }^{16}$, sobre todo cuando su lectura se realiza durante la eucaristía.

Esta nueva hermenéutica de la Biblia es sin duda fruto del Vaticano II. Si tenemos presente que la celebración de la eucaristía es el lugar por excelencia para escuchar la Palabra ${ }^{17}$ y consideramos que en este espacio se ha concretado como en ningún otro la idea de la Iglesia como pueblo de Dios que, además, lee los acontecimientos

\footnotetext{
${ }^{14}$ Francisco, "Discurso a los participantes en el Encuentro Mundial de Movimientos Populares (28 de octubre de 2014)"; Francisco, "Discurso a los participantes en el Encuentro Mundial de Movimientos Populares (7 de diciembre de 2016)".

${ }^{15}$ La versión ilustrada de la teología de la liberación predominó en sus primeros años; pero ya en sus comienzos también se dio en ella una valoración de la sabiduría del pueblo como instancia fundamental de su elaboración. Ver a Gutiérrez, Teología de la liberación. Perspectivas, 58-59; y Scannone, "El método de la teología de la liberación", 374.

${ }^{16}$ Richard, "Interpretación latinoamericana de la Biblia. Realidad, método, prospectiva”, 16; Noguez, "Hermenéutica bíblica latinoamericana. A 50 años de la II Conferencia General del Episcopado Latinoamericano", 246.

${ }^{17}$ Konings, “O Sínodo da Palavra de Deus”, 26.
} 
y las vidas en vista a reconocer los signos de los tiempos, concluimos que la llamada lectura popular de la Biblia es fiel a las cuatro grandes constituciones del Concilio y responde exactamente a la intención de aggiornamento del Vaticano II. Esto es, y dicho en breve: liturgia participativa, acceso universal a la Palabra de Dios, Iglesia pueblo de hermanos y hermanas iguales en dignidad, y apertura a la realidad histórica en su dimensión trascendente.

En estas comunidades solidarias se ha dado, según Pablo Richard, una lectura de la Palabra cuyo objetivo es "devolver la Biblia al pueblo de Dios, pues allí nació y ahí vive el sujeto de su propia interpretación” ${ }^{18}$. El mismo Richard piensa que los pobres son los intérpretes por excelencia de la Biblia porque a ellos fue revelado el Evangelio ${ }^{19}$.

Severino Croatto opina prácticamente lo mismo. Al biblista argentino no le parece exagerado "afirmar que los pobres y los oprimidos poseen la 'pertenencia' y la pertinencia’ más adecuada para releer el mensaje de la Biblia” ${ }^{20}$. A ellos les pertenece, a nadie le es más pertinente. Los biblistas latinoamericanos renuncian claramente a tener ellos la última palabra sobre la interpretación de la Biblia.

Para Carlos Mesters, "interpretar la Escritura no es una actividad informativa exclusiva del exégeta que estudió para ello, sino una actividad comunitaria a la cual todos deben contribuir, cada uno a su modo, inclusive el exégeta" ${ }^{21}$. Esta, sin el auxilio del Espíritu que habita en la comunidad, sería imposible ${ }^{22}$.

Otro asunto característico -clave en los biblistas latinoamericanos- es otorgar suma importancia a la anterioridad de la Palabra de Dios respecto del texto que la custodia. Este sirve de criterio para interpretarla. Lo fundamental es saber qué quiere decir Dios en el presente a sus lectores a través de sus vidas y en los acontecimientos que les afectan. Uno es el "libro de la vida", insisten, y otro "el libro de la Biblia", y en ambos habla Dios ${ }^{23}$. Dios escucha, pero también habla ${ }^{24}$. La "verdad plena" del texto bíblico emerge en la lectura fecundada por la experiencia actual de Dios en la vida ${ }^{25}$. Todo esto es posible porque los pobres creen que la Biblia es efectivamente la Palabra

\footnotetext{
${ }^{18}$ Richard, "Un nuevo espacio para la Palabra de Dios", 255.

${ }^{19}$ Ibíd., 13.

${ }^{20}$ Croatto, "La contribución de la hermenéutica bíblica a la Teología de la liberación”, 59-60.

${ }^{21}$ Mesters, "Oír lo que el Espíritu dice a las iglesias. Interpretación popular de la Biblia en el Brasil”, 145; Mesters, "Leitura popular da Bíblia", 535.

${ }^{22}$ Mesters, "O projeto Palabra-vida. A leitura fiel da Bíblia de acordo com a tradição e o magistério da Igreja”, 459.

${ }^{23}$ Richard, "Un nuevo espacio para la Palabra de Dios", 249.

${ }^{24}$ Konings, "O Sínodo”, 25.

${ }^{25}$ Konings, "Ler a Bíblia com o povo e como povo", 31.
} 
de Dios. La fe es fundamental para su lectura. "Sin ella, el pueblo ya no tendría más ningún interés por la Biblia”"26.

De aquí la gravedad de que la jerarquía eclesiástica y el clero hayan dejado caer las comunidades eclesiales de base, cuando no las liquidaron simplemente. Los cambios culturales, por otra parte, también han minado comunidades de todo tipo ${ }^{27}$. Sea por esto o aquello, la desaparición de estas comunidades compromete en la actualidad la recepción eclesial más rica del Concilio.

\section{Definición y método de la teología de la liberación}

La teología de la liberación se planteó desde un comienzo como "un nuevo modo" de hacer teología ${ }^{28}$. Una mirada atenta al uso de la expresión, sin embargo, deja la impresión de que no todos los teólogos entienden lo mismo al respecto. Por cierto, Agenor Brighenti ha probado que el método ver-juzgar-actuar con el cual tanto se la ha identificado no es solo europeo, sino que se utilizó en América Latina aun antes del Concilio ${ }^{29}$. La gran novedad, por tanto, ha podido ser la importancia que se ha dado a este método en el continente y los resultados a que ha llevado.

Los autores, cuando hablan de un "nuevo modo" de hacer teología suelen remitirse a Gutiérrez. Este, en su obra Teología de la liberación. Perspectivas (1972), formula la idea en estos términos:

Por todo esto la teología de la liberación nos propone, tal vez, no tanto un nuevo tema para la reflexión, cuanto una nueva manera de hacer teología. La teología como reflexión crítica de la praxis histórica es así una teología liberadora, una teología de la transformación liberadora de la historia de la humanidad y, por ende, también, de la porción de ella -reunida en ecclesia- que confiesa abiertamente a Cristo. Una teología que no se limita a pensar el mundo, sino que busca situarse como un momento del proceso a través del cual el mundo es transformado: abriéndose -en la protesta ante la dignidad humana pisoteada, en la lucha contra el despojo de la inmensa mayoría de los hombres, en el amor que libera, en la construcción de una nueva sociedad, justa y fraternal-al don del Reino de Dios. ${ }^{30}$

\footnotetext{
${ }^{26}$ Mesters, "O projeto Palabra-vida. A leitura fiel da Bíblia de acordo com a tradição e o magistério da Igreja”, 452. Traducción propia.

${ }^{27}$ Legorreta, "La erosión en las formas comunitarias tradicionales en la Modernidad/Posmodernidad", 107-132.

${ }^{28}$ Costadoat, "El método de la teología latinoamericana", 241-272.

${ }^{29}$ Brighenti, "Raíces de la epistemología y del método de la teología latinoamericana”, 207-254.

${ }^{30}$ Gutiérrez, Teología de la liberación. Perspectivas, 72.
} 
En otra ocasión, en la misma obra, Gutiérrez define la teológica de la liberación como "una reflexión crítica de la praxis a la luz de la Palabra de Dios ${ }^{31}$. Después de años de lecturas de los teólogos latinoamericanos, yo mismo me atrevo a proponer, en línea con Gutiérrez, una definición más precisa: es una reflexión crítica sobre la praxis (en el más amplio de los sentidos) de cristianos y cristianas pertenecientes a colectivos humanos oprimidos, realizada por teólogos y teólogas comprometidos con su liberación que se valen de los instrumentos de conocimiento de la realidad de las ciencias sociales, y discernida en virtud de la tradición de la Iglesia.

Las siguientes serían, a mi parecer, las nociones teológicas principales que los autores han explicitado y desarrollado después de Gutiérrez:

1. El objeto de reflexión crítica es la praxis. Por cierto, la teología latinoamericana de la liberación pretende ser crítica de sus propios fundamentos. Es en este sentido teología científica; pero es crítica, sobre todo, de las praxis y de las estructuras de opresión histórica, de la praxis de la Iglesia que coopera ideológicamente en la configuración de una sociedad injusta, e incluso crítica de la praxis de los cristianos comprometidos con la liberación de los pobres.

En los últimos años, desde Medellín hasta nuestros días, la teología latinoamericana de la liberación, por una parte, ha extendido el concepto de praxis al mundo-de-la-vida de sujetos colectivos y, por otra, ha puesto énfasis en que la praxis verdaderamente liberadora es una praxis espiritual. Por esto, si el conocimiento de la naturaleza de la opresión de las víctimas depende en buena medida de las ciencias sociales, en última instancia depende de un discernimiento de la acción del Espíritu en los acontecimientos ${ }^{32}$.

2. El sujeto de esta reflexión ha de ser un "teólogo orgánico"ş. El teólogo, sea artesanal o profesional, es en primer lugar un cristiano. La teología latinoamericana de la liberación exige fe al teólogo. El objeto primero de esta teología no es la tradición (fides quae), sino la praxis espiritual actual de los cristianos (fides qua). Se trata de una

${ }^{31}$ Ibíd., 32; ver también 22, 37, 61-70, 72, 126, 187. Gutiérrez ha distinguido en su método dos momentos: un "acto primero" (práctica y mística) y un "acto segundo" (reflexión teológica). Ver a Gutiérrez, Hablar de Dios desde el sufrimiento del inocente, 17. Sobrino, en continuidad con Gutiérrez, ofrece una definición de la teología de la liberación que ha tenido gran impacto. Ver a Sobrino, "Teología en un mundo sufriente. La teología de la liberación como 'intellectus amoris", 243-266; Boff, "Epistemología y método de la teología de la liberación”, 89; Scannone "El método de la teología de la liberación”, 369-399; Trigo, "El método teológico", 135-230; Boff, “¿Qué es hacer teología desde América Latina?”, 129-154; Codina, ¿Qué es la teología de la liberación?; González, Trinidad y liberación.

32 Trigo, "El método teológico", 174.

${ }^{33}$ Gómez Hinojosa, “Teólogo de la liberación, ¿'intelectual orgánico’?” 7-18; Costadoat, "El/la teólogo/a de la liberación latinoamericano/a: ¿̨un intelectual orgánico?” 9-32. 
teología inductiva que parte de la base de que el científico está comprometido, está implicado, no es neutral respecto del objeto de su estudio, sino - por el contrario-que para hacer teología es indispensable tomar partido por la liberación de los oprimidos.

A propósito de la cristología, Jon Sobrino sostiene que "conocer a Cristo es, en último término, seguir a Cristo" ${ }_{34}$. Por esto, el teólogo profesional debe servir, como quien ocupa el último lugar en la actividad reflexiva, a los esfuerzos de los cristianos que -en virtud de su cristianismo- están obligados a pensar su vida a la luz de la fe. De aquí que la reflexión científica de los teólogos de la liberación ha de hundir sus raíces en la sabiduría popular y en los modos de relación con Dios de los colectivos oprimidos. Mención aparte merece, a este propósito, el desarrollo de la teología argentina del pueblo ${ }^{35}$.

3. Dos son las mediaciones para comprender esta praxis: una es la fe de la Iglesia (fides quae) contenida en sus fuentes: la autoridad de la Sagrada Escritura, de las tradiciones de Cristo y los apóstoles, de la Iglesia Católica, de los concilios, de la Iglesia romana, de los santos antiguos, de los teólogos escolásticos; y los loci alieni ("lugares ajenos"): la razón natural, la autoridad de los filósofos y de la historia humana ${ }^{36}$. Estas fuentes contienen y nos transmiten la que ha sido una experiencia de Dios y, por lo mismo, fungen como criterios de discernimiento de lo que Dios va revelando a lo largo de los siglos.

La segunda mediación son las ciencias sociales, que hacen posible comprender la realidad histórico-cultural en la que se entrevera esa praxis cristiana. Gracias a ellas se pueden conocer los mecanismos estructurales de la opresión. En los años 60, los teólogos recurrieron a las teorías de la dependencia que postulaban que América Latina debía liberarse de las potencias desarrolladas. Si el desarrollismo prometía que los países subdesarrollados seguirían el curso de los desarrollados, las teorías de la dependencia sostenían, por el contrario, que estos eran subdesarrollados precisamente porque las naciones ricas eran desarrolladas ${ }^{37}$. Así las cosas, en vez de estrechar los vínculos, lo que había que hacer era romperlos. En los años sucesivos, las teologías de la liberación han acudido al auxilio de nuevas disciplinas: la historia, la antropología, las ciencias del medioambiente, las teorías de género y otras.

\footnotetext{
${ }^{34}$ Sobrino, Jesucristo liberador. Lectura histórico-teológica de Jesús de Nazaret, 57.

${ }^{35}$ Azcuy, "Introducción", 9-49.

${ }^{36}$ Hünermann, Fe, tradición y teología como acontecer de habla y verdad, 212.

${ }^{37}$ Dussel, “Teología de la liberación y marxismo”, 115-144.
} 
No se puede olvidar, sin embargo, que además de tener un origen por los años 60 y además de depender en buena medida del giro inductivo de la teología, lo que origina la teología latinoamericana de la liberación es la constatación de la opresión de los pobres como hecho repudiado por Dios. Gustavo Gutiérrez sostiene que ella nace del imperativo de anunciar el Evangelio a "pueblos dominados, clases sociales explotadas, razas despreciadas y culturas marginadas" ${ }^{38}$.

El mismo teólogo sostiene que las preguntas fundamentales por Dios en América Latina son las siguientes: “¿Cómo anunciar el Dios de la vida a personas que sufren una muerte prematura e injusta? ¿Cómo reconocer el don gratuito de su amor y de su justicia desde el sufrimiento inocente? ¿Con qué lenguaje decir a los que no son considerados personas que son hijas e hijos de Dios?" ${ }^{39}$. Los demás teólogos siguen en esto los pasos de Gutiérrez ${ }^{40}$. Hablar de pobres en América Latina, en todo caso, se entiende de modo análogo. Pobres hay de muchos tipos ${ }^{41}$.

En fin, a cincuenta años de Medellín cabe tener presente que en la actualidad se ha hecho muy complejo saber, por una parte, qué está ocurriendo realmente en el mundo y, por tanto, cuál puede ser la praxis social y política que ha de emprenderse para liberar a gran cantidad de nuevas víctimas. Debe subrayarse, a este respecto, la importancia del giro de Leonardo Boff hacia la ecología ${ }^{42}$. La posibilidad de una catástrofe mundial que afecte en primer lugar a los pobres es ya una realidad. A tal dificultad se suma la del arraigo eclesial que la misma teología latinoamericana de la liberación pide de toda teología.

Por otra parte, se constata un problema eclesial. La teología latinoamericana tiene actualmente dificultades para arraigar en una Iglesia cuya institucionalidad necesita cambios profundos. Se está lejos, por ejemplo, de la reforma estructural que se haga cargo de la demanda de autonomía de las iglesias regionales señalada en su momento por Rahner ${ }^{43}$. En lo inmediato urge crear mecanismos que prevengan y reparen los abusos sexuales del clero y su encubrimiento de parte de la jerarquía católica.

\footnotetext{
${ }^{38}$ Gutiérrez, Teología de la liberación. Perspectivas, 22.

${ }^{39}$ Gutiérrez, Hablar de Dios desde el sufrimiento del inocente, 18-19.

${ }^{40}$ Costadoat, "La pregunta por Dios en la teología de la liberación”, 29-57.

${ }^{41}$ Celam, "Aparecida" 65.

${ }^{42}$ Boff, Ecología: grito de la tierra, grito de los pobres; Florio, Teología de la vida en el contexto de la evolución $y$ de la ecologia; Guridi, Ecoteología.

${ }^{43}$ Schickendantz, "De una Iglesia occidental a una Iglesia mundial. Una interpretación de la reforma eclesial”.
} 


\section{Nuevas teologías latinoamericanas de la liberación}

Bajo diversos respectos, hoy puede hablarse en América Latina de "la" o "las" teologías de la liberación. En seguida se reseñan dos teologías que en las últimas décadas han enriquecido extraordinariamente la teología latinoamericana de la liberación ${ }^{44}$. Se verá también que en lo fundamental comparten el mismo método que el de los teólogos de la primera hora.

\section{El método en la teología india}

La teología india no ha desarrollado un método propio. Lo que tiene "son pasos metodológicos" ${ }^{45}$. Eleazar López, teólogo zapoteca y el autor más relevante en el tema, ofrece una definición de esta teología:

La teología india es el conjunto de experiencias y de conocimientos religiosos que los pueblos indios poseen y con los cuales explican, desde milenios hasta el día de hoy, su experiencia de fe, dentro del contexto de su visión global del mundo y de la visión que los demás tienen de estos pueblos. La teología India es, por tanto, un acervo de prácticas religiosas y de sabiduría teológica popular del que echan mano los miembros de los pueblos indios para explicarse los misterios nuevos y antiguos de la vida. Por eso no se trata de algo nuevo ni de un producto propiamente eclesial, sino de una realidad muy antigua que ha sobrevivido a los embates de la historia. ${ }^{46}$

A algunos ha parecido que esta no es teología, sino sabiduría; pero ella comparte, en términos generales, el método de la teología latinoamericana de la liberación. Su punto de partida es la situación de opresión centenaria de los indígenas, pueblos vencidos y "empujados a la extinción" ${ }^{47}$. La teología india reclama justicia para estos pueblos y un lugar digno en la misma Iglesia ${ }^{48}$. También es inductiva, pues parte de la experiencia de Dios de los indígenas ${ }^{49}$.

\footnotetext{
${ }^{44}$ Otras teologías latinoamericanas muy significativas han sido la ecoteología de Leonardo Boff, recién señalada, y la teología argentina del pueblo, mencionada más arriba.

45 "En el proceso de elaboración de la teología india no existe una metodología como tal, bien sistematizada; lo que existe son pasos metodológicos que responden a la creatividad de los sujetos teológicos" (Sarmiento, Caminos de la teología india, 154).

${ }^{46}$ López, "La teología india y su lugar en la Iglesia”. Ver también a: Tomichá, "Aportes de los pueblos indígenas a la iglesia y a la teología hoy”, 96-105; Estermann (dir.,), Teología andina; Irarrázaval, Indagación cristiana en los márgenes. Un clamor latinoamericano.

${ }^{47}$ López, Espiritualidad y teología de los pueblos amerindios, 10.

${ }^{48}$ López, "México: teología india, un aporte para la vida del mundo".

${ }^{49}$ López, "la teología india en la Iglesia. Un balance después de Aparecida", 87.
} 
Lo mismo que la teología de la liberación, la teología india relaciona un acto primero, la praxis, y un acto segundo, la reflexión crítica ${ }^{50}$. Además, da enorme importancia al quehacer teológico de las mismas comunidades. Fundamentalmente son estas las que hacen teología ${ }^{51}$. Los teólogos profesionales colaboran con las comunidades, arriesgando siempre traicionarlas con conceptualizaciones que se alejen de su realidad.

Parte importante de la incomprensión de la teología india también tiene que ver con su lenguaje mítico, simbólico y ritual. Su conceptualización es diferente. No tiene la preocupación "por elaborar ideas claras y distintas"52. Eleazar López es consciente de la dificultad que tal planteamiento significa para la comunicación de esta teología con las demás ${ }^{53}$.

Por último, es muy característico de la teología india la autoconciencia histórica de su desarrollo. En su larga historia, López celebra que la teología india cristiana haya ido saliendo de la clandestinidad para constituirse en un verdadero aporte a la Iglesia Católica para la inculturación del Evangelio ${ }^{54}$.

\section{El método en la teología feminista de la liberación}

La teóloga feminista que seguramente ha dado más importancia al tema del método es Consuelo Vélez ${ }^{55}$. Según esta teóloga colombiana, la teología feminista se beneficia del método de la teología de la liberación. No obstante -recuerda Vélez-, la teología de la liberación "mantuvo 'invisibilizada' la realidad de la mujer hasta una

\footnotetext{
${ }^{50}$ López “Teologías indias de hoy”, 37.

${ }^{51}$ López, "Hacer teología desde la pastoral”; López, “Teología india hoy”, 78.

${ }^{52}$ López, "La teología india”, 88.

${ }^{53}$ Eleazar López da cuenta de un importante diálogo sobre este tema con Luis Ladaria, entonces secretario de la Congregación para la Doctrina de la Fe (López, Espiritualidad y teología de los pueblos amerindios, 10-11).

${ }^{54}$ López La teología india y su lugar en la Iglesia, 9.14; López, "La teología india en la Iglesia. Un balance después de Aparecida”, 93.

${ }^{55}$ Otras teólogas importantes son: Aquino, Nuestro clamor por la vida. Teología latinoamericana desde la perspectiva de la mujer; Tepedino, Las discípulas de Jesús; Gebara, "Teología de la liberación y feminismo"; Bingemer, "La mujer teóloga: vocación y ministerio"; Corpas de Posada, "Mujeres teólogas: ¿cuál es nuestra identidad y nuestro aporte al quehacer teológico?". La colección en cuatro tomos de Teologanda, titulada Mujeres haciendo teología, es un trabajo notable: Azcuy, Di Renzo y Lertora (coords.), Diccionario de obras de autoras en América Latina, el Caribe y Estados Unidos; Azcuy, Mazzini y Raimondo (coords.), Antología de textos de autoras en América Latina, el Caribe y Estados Unidos; Azcuy, García Bachmann y Lértora (coords.), Estudios de Autoras, en América Latina, el Caribe y Estados Unidos; Azcuy, Bedford y Palacio (coords.), Huellas y cruces del camino.
} 
década posterior" ${ }^{56}$. También esta teología ha debido luchar por su reconocimiento. Para Vélez, la teología feminista es inductiva:

...nace como reflexión dentro de los cánones de la teología de la liberación. Usa la metodología del ver-juzgar-actuar: parte de la realidad de la mujer, la juzga a la luz de la Palabra de Dios y toma decisiones respecto de las acciones que deben transformar esa realidad. ${ }^{57}$

Este es un "programa de acción" que pretende "partir de la realidad de las mujeres, iluminarla desde la fe y volver a ella para transformarla"ss.

Vélez, a este propósito, señala la importancia que tiene la teoría de género ${ }^{59}$. La perspectiva de género ha abierto a las mujeres la posibilidad de verse a sí mismas de otro modo: "De ser seres-para-los-otros (sentido patriarcal) se descubren como seres-para-sí, es decir, son capaces de enfrentar la opresión, mejorar sus condiciones de vida, ocuparse de sí mismas y convertirse por esa vía en protagonistas de su vida"60. La crítica de la teología feminista a la sociedad patriarcal y a "las normas, tradiciones y estereotipos que de ella derivan" tiene por objeto "una revisión radical de todas esas formas de opresión" ${ }^{61}$. Su intención ulterior es liberar a mujeres y a hombres. No sería posible de otro modo: "La teología feminista comunica la buena noticia de la igualdad fundamental entre todos los seres humanos" 62 . Dos son, para Vélez, las principales realizaciones de esta teología. La primera consiste en los principios fundamentales que ha podido asentar:

Entre los principios básicos podemos señalar está la afirmación fundamental de la igualdad entre varones y mujeres, el imperativo ético de denunciar toda situación de subordinación y violencia vivida por las mujeres, la necesidad de reconstruir la historia de las mujeres, tanto en los textos bíblicos como en la historia de nuestros pueblos, la apropiación de las categorías críticas feministas de género como opción epistemológica en el quehacer teológico, la incorporación de estudios interdisciplinares e interculturales para articular la racionalidad afectiva, la estética y la sabiduría del imaginario popular. ${ }^{63}$

\footnotetext{
${ }^{56}$ Vélez, "Teología feminista latinoamericana de la liberación: balance y futuro".

${ }^{57}$ Vélez, El método teológico. Fundamentos, especializaciones, enfoques, 224.

${ }^{58}$ Vélez, "Teología feminista latinoamericana de la liberación: balance y futuro", 1811.

${ }^{59}$ Vélez, "Teología de la mujer, feminismo y género", 560.

${ }^{60}$ Ibíd., 562.

${ }^{61}$ Vélez, El método teológico. Fundamentos, especializaciones, enfoques, 224.

${ }^{62}$ Vélez, “Teología feminista latinoamericana de la liberación: balance y futuro”, 1810.

${ }^{63}$ Ibíd., 1806.
} 
Sobre todo -sostiene Vélez-, esta teología ha dado importancia a temas nuevos: la vida cotidiana, lo lúdico, la fiesta, el cuerpo, la sexualidad y el placer, todo lo cual ha merecido ser reflexionado en la óptica de la liberación del sexismo y el término de la violencia sexual.

\section{¿Hacia un nuevo concepto de revelación?}

El desarrollo de la teología latinoamericana de la liberación como teología de la historia, de los acontecimientos o de los signos de los tiempos ha supuesto un modo de entender el fenómeno de la revelación que parece novedoso y que, en todo caso, merece ser profundizado. Si tradicionalmente la teología ha identificado la revelación con la paretheke, esto es, la Escritura y la tradición apostólica ${ }^{64}$, la teología latinoamericana de la liberación ha subrayado que ella adquiere toda su importancia en la experiencia actual de Dios. La Palabra de Dios, en este sentido, apela en el presente a los seres humanos, tal como lo hizo en el pasado en Jesucristo.

En América Latina se ha procurado conocer esta Palabra mediante el método del ver-juzgar-actuar. Mediante este instrumento, los teólogos latinoamericanos, con el magisterio, por la senda de Gaudium et spes, han descubierto en los pobres la irrupción misma de Dios y han terminado por afirmar que la opción por los pobres es esencial al cristianismo ${ }^{65}$.

La teología latinoamericana de la liberación, por esta vía, ha insistido en que la historia, y particularmente los pobres, constituyen un "lugar teológico"66. El uso de esta expresión ha sido sin embargo complejo. El catolicismo, durante siglos, ha utilizado el sistema de los loci theologici de Melchor Cano para establecer qué ha de entenderse como revelado ${ }^{67}$, sobre todo, desde el momento en que la Reforma protestante puso a la Iglesia al borde del subjetivismo.

Sin embargo, se han suscitado malos entendidos con la utilización de los teólogos latinoamericanos de la expresión "lugar teológico" sin hacer referencia suficiente a las distinciones de Cano entre lugares "propios" y "ajenos", ni indicar que la "historia" es entendida como acontecimiento y no como archivos, textos, etc. para el estudio histórico (que es el sentido que Cano le dio).

${ }^{64}$ Hünermann, Fe, tradición y teología como acontecer de habla y verdad, 22.

${ }^{65}$ Gutiérrez, Teología de la liberación. Perspectivas, 21. La Conferencia de Aparecida hizo suya la idea de Benedicto XVI de considerar implícita la opción por los pobres en la fe cristiana (392-393).

${ }^{66}$ Costadoat, "El 'lugar teológico' en Jon Sobrino", 23-49; ver Aquino, "Dios habla hoy. En busca de un nuevo concepto de revelación”, 171-202; Costadoat, "Novedad de la teología de la liberación en la concepción de la revelación”, 27-45.

${ }^{67}$ Hünermann, Fe, tradición y teología como acontecer de habla y verdad, 205-214. 
Francisco de Aquino ha advertido un "mutación semántica" que no todos los teólogos han captado ${ }^{68}$. El caso de la disputa entre Jon Sobrino y la Congregación para la Doctrina de la Fe, que terminó con la "Notificación" en contra de Sobrino, es un buen ejemplo de la complejidad del cambio de paradigma de una teología deductiva a una inductiva. Lo es, sobre todo, porque lo que estuvo en juego en el enfrentamiento de las posiciones fue una nueva manera de entender la revelación, y no solo un uso equívoco de los términos ${ }^{69}$.

En esta disputa con la Congregación, Sobrino no se expresó con la misma claridad con que lo ha hecho en otras oportunidades. Como otros teólogos, Sobrino pudo considerar la historia como mero contexto a partir del cual comprender esta revelación. Lo verdaderamente novedoso, en su caso, fue concebir un habla de Dios que no proviene de las Escrituras sino de la vida y de los acontecimientos del presente. Sostiene el teólogo de la UCA:

El lugar de la cristología es, pues, importante para que esta use adecuadamente sus fuentes del pasado y del presente. Sin embargo, no hemos mencionado todavía en qué consiste formalmente ese lugar y cuál es su realidad material. En nuestra opinión, aquí se da la opción fundamental. Para unas cristologías, el lugar teológico son sustancialmente textos, aunque tengan que ser leídos en un lugar físico y aunque se tengan en cuenta las exigencias nuevas de la realidad, los signos de los tiempos en sentido histórico-pastoral. Para la cristología latinoamericana, el lugar teológico es ante todo algo real, una determinada realidad histórica en la cual se cree que Dios y Cristo se siguen haciendo presentes; por ello, son lugar teologal antes que lugar teológico, y lugar desde el cual se pueden releer más adecuadamente los textos del pasado. ${ }^{70}$

En línea con Sobrino, los biblistas latinoamericanos también han reconocido una revelación actual de Dios y su prioridad sobre el texto bíblico, lo que no deja de ser sorprendente. Afirma Carlos Mesters:

A lo largo de estos años, lentamente, desde dentro de este interés renovado por la Biblia, surgió una nueva concepción de la revelación que es de gran importancia para entender la interpretación popular, a saber: ¡Dios no habló solo en el pasado, sino que continúa hablando hoy!?1

\footnotetext{
${ }^{68}$ De Aquino Junior, Teologia em saida para as periferias, 64.

${ }^{69}$ Costadoat, "El 'lugar teológico' en Jon Sobrino”, 23-49.

${ }^{70}$ Sobrino, Jesucristo liberador. Lectura histórico-teológica de Jesús de Nazaret, 46-47; ver a Herrera Aceves, "La historia, lugar teológico dentro de la experiencia eclesial", 341-352.

${ }^{71}$ Mesters, "Oír lo que el Espíritu dice a las iglesias. Interpretación popular de la Biblia en el Brasil", 144; ver a Richard "Teología en la teología de la liberación”, 204; Croatto, "La contribución de la hermenéutica bíblica a la teología de la liberación”, 45-69.
} 
La teología latinoamericana de la liberación aún debe clarificar qué significa que la Palabra de ayer sea la de hoy y que su apelación actual deba ser considerada prioritaria. Los teólogos han insistido en la prioridad de la ortopraxis sobre la ortodoxia ${ }^{72}$. Lo que ha quedado pendiente es repensar los loci de Cano a partir del descubrimiento de la historicidad radical del ser humano, de la salvación y de la revelación.

En este horizonte, el recurso a las ciencias modernas mencionado arriba adquiere una importancia mucho mayor que la que ha tenido hasta hace poco. Estas no han de aplicarse solo a los textos, lo cual no es poco en el caso de la exégesis. Muchas otras ciencias pueden socorrer la labor hermenéutica de desentrañar el fenómeno del habla de Dios en la historia y en la tradición de la Iglesia.

\section{A modo de conclusión: una teología de la historia in fieri}

1. La teología latinoamericana de la liberación es una teología de la historia. En plena posmodernidad esta afirmación encenderá las alarmas contra los "hegelianismos"; pero esta teología no pretende tener el concepto de la historia ni realizarlo mediante una praxis excogitada a priori. La teología latinoamericana de la liberación supone que la historia tiene sentido para quienes no parece tenerlo. Ella debe probar teóricamente que Dios ama a los pobres.

Es una teología de la historia porque se concentra en pensar la acción auténticamente histórica de un Dios que no interviene la historia, sino que actúa por medio de la praxis de seres libres y responsables. Los teólogos de la liberación prometen a las víctimas de los diversos tiempos una razón (una razón que implica a toda la humanidad) para resistir y cambiar su destino. Ellos no poseen el "logos" de la historia, pues este logos es Dios mismo en su misterio, a saber, como Dios de los pobres. La teología latinoamericana de la liberación apuesta por ellos contra la pobreza, entendida esta como pecado, como realidad que, a los ojos de un cristiano, no debiera considerarse normal.

En la medida en que esta teología ha podido ahondar en su índole espiritual ha debido reconocer en los mismos pobres a los primeros responsables de su liberación y de su teología. La teología latinoamericana de la liberación es una teología de la historia porque, contra todas las apariencias, sostiene que la lucha de los pobres por la vida tiene un valor eterno y que nadie mejor que ellos mismos aprenden y saben cómo vivir y pensar su vida a la luz de su fe. Los teólogos latinoamericanos han

${ }^{72}$ Gutiérrez, Teología de la liberación. Perspectivas, 66; Segundo, "Libertad y liberación”, 380; Sobrino, "Centralidad del Reino de Dios en la Teología de la liberación”, 489; Pastor, "Ortopraxis y ortodoxia”, 185-201; Galilea, "Cristología y ortopraxis cristiana”, 16-20. 
resaltado la necesidad de que la teología hunda sus raíces en el modo de los pobres de creer y de pensar. Ellos, como "teólogos orgánicos", han querido ponerse al servicio de la sabiduría/teología de los pobres.

Este empalme con el quehacer teológico de los pobres es una característica de la cientificidad de la teología latinoamericana de la liberación. También lo es su diálogo con las más diversas ciencias sociales. El conocimiento "artesanal" de la realidad no basta para introducir cambios mayores e idealmente estructurales contra los mecanismos de opresión. Su método es histórico. La apertura de la teología latinoamericana de la liberación a una realidad irreductible a conceptualizaciones definitivas es equivalente a la de las demás ciencias y, por esta razón, es posible entre ellas un diálogo y una crítica.

Por esto mismo, si las ciencias sociales no son neutras sino asumen presupuestos intencionales y, por ende, se prestan para tal o cual uso ideológico, la teología también se expone a la crítica. Esta admite diversas configuraciones e importa los conflictos propios de la sociedad. La teología latinoamericana de la liberación es conflictiva. Su opción por los pobres la localiza en un "lugar social" determinado y la hace "parcial". La apuesta por una fraternidad universal es para ella un objeto de fe en sentido estricto. Lo que los teólogos latinoamericanos captan prima facie es una lucha por la vida y contra la injusticia, y ponen su teología al servicio de unos y, a veces, en contra de otros.

La teología latinoamericana de la liberación, de acuerdo con su método, es fiel a sí misma en la medida en que -a cincuenta años de Medellín- ha podido sustentar las luchas de liberación de nuevos sujetos colectivos oprimidos. No ha podido ser de otro modo. Esta es parte de su novedad. La teología feminista y la teología india, por ejemplo, comparten su método con resultados tan disímiles como ricos.

2. La pretensión histórica de la teología latinoamericana de la liberación -su "interés" confesado por liberar a las víctimas de injusticias históricas- no es arbitraria ni ideológica. Pudiera serlo, si no se basara en las fuentes de la revelación. Los teólogos de la liberación establecen una circularidad hermenéutica tanto entre los textos bíblicos y los acontecimientos actuales, como entre estos y los acontecimientos liberadores de los cuales habla la Biblia.

Podrá discutirse la calidad de tal o cual interpretación de la Palabra de Dios, pero el argumento es fundado desde un punto de vista científico. El Dios de la Biblia es el Dios de los pobres. Sin la Biblia, la Iglesia no habría descubierto en los pobres la manifestación actual de Dios. Estos, a su vez, han hecho posible redescubrir que Dios opta por ellos, verdad tantas veces oculta a las teologías-de-teologías atentas al credo cristiano (fides quae) pero no a la experiencia de fe de los creyentes (fides qua). 
3. Una de las mayores novedades de la teología latinoamericana de la liberación estriba en sostener que la historia, en particular la de los pobres, constituye un "lugar teológico”. No es nuevo que haya científicos sociales que crean que desde el contexto se puedan entender mejor los textos. Los teólogos latinoamericanos hacen suya la hermenéutica del siglo XX. El uso del término "lugar teológico" para referirse a la historia, sin embargo, ha dado pie a malos entendidos.

La teología latinoamericana de la liberación, al redescubrir la índole radicalmente histórica de la revelación, postula que Dios, que habló en acontecimientos del pasado, continúa hablando en los del presente, independientemente de que se cuente con la Biblia que, sin embargo, hace de criterio último de interpretación para distinguir en los hechos la voz de Dios "en las múltiples voces de nuestro tiempo"73. La tarea metodológica pendiente, a este propósito, consiste en desplegar la articulación de la Palabra de Dios con el presente.

Este presente, según los teólogos latinoamericanos, tiene una densidad teológica que la teología tradicional no le reconoció; pero hasta ahora la teología latinoamericana de la liberación, a este respecto, permanece en los "titulares" que anuncian la noticia. Que Dios hable hoy y que el habla actual de Dios a través de su Espíritu tenga prioridad sobre la misma Escritura es un postulado y una práctica en las comunidades de base, pero no es todavía un tratado de teología fundamental o algo parecido. En este sentido, la teología latinoamericana de la liberación como teología de la historia necesita una estructuración mayor.

\section{Referencias}

Aquino, María del Pilar. "Dios habla hoy. En busca de un nuevo concepto de revelación”. Franciscanum, LX/169 (2018): 171-202. - Nuestro clamor por la vida. Teología latinoamericana desde la perspectiva de la mujer. Costa Rica: Departamento Ecuménico de Investigaciones, 1992.

Azcuy, Virginia. "Introducción”. En Lucio Gera. La teología argentina del pueblo, editado por V. Azcuy, 9-49. Santiago: Universidad Alberto Hurtado, 2015.

Azcuy, Virginia; Gabriela Di Renzo; y Celina Lértora (coords.). Diccionario de obras de autoras en América Latina, el Caribe y Estados Unidos. Vol. 1, Buenos Aires: San Pablo, 2007.

${ }^{73}$ Concilio Vaticano II, "Constitución pastoral Gaudium et spes sobre la Iglesia en el mundo actual (1965)" 44 . 
Azcuy, Virginia; Marcela Mazzini; y Nancy Raimondo (coords.). Antología de textos de autoras en América Latina, el Caribe y Estados Unidos. Vol. 2. Buenos Aires: San Pablo, 2008.

Azcuy, Virginia; Mercedes García Bachmann; y Celina Lértora (coords.). Estudios de autoras, en América Latina, el Caribe y Estados Unidos. Vol. 3. Buenos Aires: San Pablo, 2009.

Azcuy, Virginia; Nancy Bedford; y Marta Palacio (coords.). Huellas y cruces del camino, Vol. 4. Buenos Aires: Centro de Estudios Salesiano de Buenos Aires, 2013.

Bingemer, Maria Clara L. "La mujer teóloga: vocación y ministerio". Christus 270 (2000): 21-28.

Boff, Clodovis. "Epistemología y método de la teología de la liberación”. En Mysterium liberationis. Conceptos fundamentales de la teología de la liberación, por Ignacio Ellacuría y Jon Sobrino, Vol. 1, 85-89. Madrid: Trotta, 1990.

Boff, Leonardo. Ecología: grito de la tierra, grito de los pobres. Madrid: Trotta, 1996.

. “QQué es hacer teología desde América Latina?”. En Liberación y cautiverio: debates en torno al método de la teología en América Latina, dirigido por Enrique Ruiz Maldonado, 129-154. México D.F.: Comité Organizador, 1975.

Brighenti, Agenor. "Raíces de la epistemología y del método de la teología latinoamericana”. Medellin 78 (1994): 207-254.

Celam. "Aparecida”. En Las cinco conferencias generales del Episcopado latinoamericano: Rio de Janeiro, Medellín, Santo Domingo y Aparecida, editado por el Consejo Episcopal Latinoamericano, 663-880. Bogotá: Celam, 2014.

Codina, Víctor. "Las iglesias del continente 50 años después del Vaticano II". En Congreso Continental de Teología, 50 años del Vaticano II. Bogotá: Paulinas, 2013. - ¿Qué es la teología de la liberación? Santiago: Rehue, 1987.

Concilio Vaticano II. "Constitución pastoral Gaudium et spes sobre la Iglesia en el mundo actual (1965)”. Vatican, http://www.vatican.va/archive/hist councils/ii vatican council/documents/vat-ii const 19651207 gaudium-et-spes sp.html (consultado el 7 de enero de 2020).

Corpas de Posada, Isabel. "Mujeres teólogas: ¿cuál es nuestra identidad y nuestro aporte al quehacer teológico?”. Franciscanum 51/151 (2009): 37-76.

Costadoat, Jorge. "El/la teólogo/a de la liberación latinoamericano/a: ¿un intelectual orgánico?” Stromata 74/1 (2018): 9-32. 
. "El 'lugar teológico’ en Jon Sobrino”. Theologica Xaveriana 181 (2016): 23-49.

- "El método de la teología latinoamericana”. En Comentario bíblico-teológico sobre Medellín, coordinado por José de J. Legorretta, 241-272. Ciudad de México: Universidad Iberoamericana, 2018.

. "Identidad de la teología de la liberación y la teología latinoamericana". Perspectiva Teológica 50/1 (2018): 19-40.

- "La pregunta por Dios en la teología de la liberación". En Trazos de Cristo en América Latina. Ensayos teológicos, 29-57. Santiago: Universidad Alberto Hurtado, 2010.

- "Novedad de la teología de la liberación en la concepción de la revelación". Teología LIV/124 (2017): 27-45.

Croatto, Severino. "La contribución de la hermenéutica bíblica a la teología de la liberación”. Cuadernos de teología 6/4 (1985): 45-69.

De Aquino Júnior, Francisco. "La Iglesia de los pobres. Del Vaticano II a Medellín y nuestros días". Revista latinoamericana de teología 87 (2012): 277-298.

. Teologia em saída para as periferias. São Paulo-Recife: Paulinas-Unicap, 2019.

Dussel, Enrique. "Teología de la liberación y marxismo". En Mysterium liberationis. Conceptos fundamentales de la teología de la liberación, por Ignacio Ellacuría y Jon Sobrino, Vol. 1, 115-144. Madrid: Trotta, 1990.

Estermann, Josef (dir.). Teología andina. 2 vols. La Paz: Iseat, 2006.

Ferrara, Ricardo y Carlos M. Galli (eds.). Presente y futuro de la teología en Argentina: homenaje a Lucio Gera. Buenos Aires: Paulinas, 1997.

Florio, Lucio. Teología de la vida en el contexto de la evolución y de la ecología. Buenos Aires: Ágape, 2015.

Francisco. "Discurso a los participantes en el Encuentro Mundial de Movimientos Populares (28 de octubre de 2014)". Vatican, http://www.vatican.va/content/ francesco/es/speeches/2014/october/documents/papa-francesco_20141028 incontro-mondiale-movimenti-popolari.html (consultado el 7 de enero de 2020).

Francisco. "Discurso a los participantes en el Encuentro Mundial de Movimientos Populares (5 de noviembre de 2016)". Vatican, http://www.vatican.va/content/ francesco/es/speeches/2016/november/documents/papa-francesco 20161105 movimenti-popolari.html (consultado el 7 de diciembre de 2020). 
Galilea, Segundo. “Cristología y ortopraxis cristiana”. Christus 39/458 (1973):16-20. . "Ejemplo de recepción selectiva y creativa del Concilio: América Latina en las conferencias de Medellín y Puebla”. En La recepción del Vaticano II, editado por G. Alberigo y J. P. Jossua, 86-101. Madrid: Cristiandad, 1987.

Gebara, Ivone. "Teología de la liberación y feminismo". Alternativas: revista de análisis y reflexión teológica 19 (2012): 53-68.

Gómez Hinojosa, José Francisco. “Teólogo de la liberación, ¿intelectual orgánico’?”. Pasos 10 (1987): 7-18.

González, Antonio. Trinidad y liberación. San Salvador: UCA, 1994.

Guridi, Román. Ecoteología. Santiago: Universidad Alberto Hurtado, 2018.

Gutiérrez, Gustavo. Hablar de Dios desde el sufrimiento del inocente. Salamanca: Sígueme, 1986.

. Teología de la liberación. Perspectivas. Salamanca: Sígueme, 1990.

Herrera Aceves, Jesús. "La historia, lugar teológico dentro de la experiencia eclesial". En Liberación y cautiverio: debates en torno al método de la teología en América Latina, editado por Enrique Ruiz Maldonado, 341-352. México D.F.: Comité Organizador, 1975.

Hünermann, Peter. Fe, tradición y teología como acontecer de habla y verdad. Barcelona: Herder, 2006.

Irarrázaval, Diego. Indagación cristiana en los márgenes. Un clamor latinoamericano. Santiago: Universidad Alberto Hurtado, 2013.

Konings, Johan. "Ler a Bíblia com o povo e como povo". Perspectiva teológica 27/71 (1995): 27-35.

. "O Sínodo da Palavra de Deus". Convergencia 44/418 (2009): 17-33.

Legorreta, Jesús de José. "La erosión en las formas comunitarias tradicionales en la Modernidad/Posmodernidad”. En Hacia otros modelos de comunidad cristiana. Ser y hacer comunidad en sociedades en cambio, coordinado por José Legorreta, 107-132. México D.F.: Universidad Iberoamericana, 2015.

López, Eleazar. Espiritualidad y teología de los pueblos amerindios. México: UNAM, 1999.

. "Hacer teología desde la pastoral". Voces 5 (1994): 126-129. 
. "La teología india en la Iglesia. Un balance después de Aparecida". Revista iberoamericana de teología 6 (2008): 87-117.

. "La teología india y su lugar en la Iglesia". Conselho Indigenista Missionário, http://www.cimi.org.br/pub/assteologica/Eleazar LATEOLOGIAINDIAYSULUGARENLAIGLESIA.pdf (consultado el 7 de enero de 2020).

. "México: teología india, un aporte para la vida del mundo". Redes cristianas, http://www.redescristianas.net/mexico-teologia-india-aporte-para-la-vida-delmundopbro-eleazar-lopez-hernandez (consultado el 7 de enero de 2020).

. "Teología india hoy". Boletin Cihev 7 (1991): 77-83.

. "Teologías indias de hoy". Christus 696 (1996): 34-40.

Luciani, Rafael. "Medellín Fifty Years Later: From Development to Liberation". Theological Studies 79/3 (2018): 566-589.

Mc Grath, Marcos. “La misión de la teología en Latinoamérica”. Anales de la Facultad de Teología 12 (1960): 13-18.

Mesters, Carlos. "Leitura popular da Bíblia”. En Dicionário do Concílio Vaticano II, coordinado por João Décio Passos y Wagner Lopes Sánchez, 533-536. São Paulo: Paulinas, 2015.

. "O projeto Palabra-vida. A leitura fiel da Bíblia de acordo com a tradição e o magistério da Igreja”. Convergencia 24/226 (1989): 451-467.

. "Oír lo que el Espíritu dice a las iglesias. Interpretación popular de la Biblia en el Brasil”. Concilium 27/233 (1991): 143-156.

Noguez, Armando. "Hermenéutica bíblica latinoamericana. A 50 años de la II Conferencia General del Episcopado Latinoamericano”. En Comentario bíblico-teológico sobre Medellín, coordinado por José de Jesús Legorretta, 241-272. Ciudad de México: Universidad Iberoamericana-Buena Prensa, 2018.

Pastor, Félix. “Ortopraxis y ortodoxia”. Selecciones de teología 30/119 (1991):185-201. Richard, Pablo. "Interpretación latinoamericana de la Biblia. Realidad, método, prospectiva”. En Comentario biblico latinoamericano. Nuevo Testamento, dirigido por Armando J. Levoratti, 11-20. Estella (Navarra): Verbo Divino, 2005.

- “Teología en la teología de la liberación”. En En Mysterium liberationis. Conceptos fundamentales de la teología de la liberación, por Ignacio Ellacuría y Jon Sobrino, Vol. 1, 201-222. Madrid: Trotta, 1990.

. “Un nuevo espacio para la Palabra de Dios". Concilium 2/335 (2010): 247-261. 
Sarmiento, Nicanor. Caminos de la teología india. Bolivia: Verbo Divino, 2000.

Scannone, Juan Carlos. "El método de la teología de la liberación”. Theologica Xaveriana 34 (1984): 369-399.

Schickendantz, Carlos. "De una Iglesia occidental a una Iglesia mundial. Una interpretación de la reforma eclesial”. Theologica Xaveriana 185 (2018): 1-28.

. "Una elipse con dos focos. Hacia un nuevo método teológico a partir de Gaudium et spes". En Teología de los signos de los tiempos latinoamericanos. Horizontes, criterios y métodos, editado por Virginia Azcuy, Carlos Schickendantz y Eduardo Silva, 53-87. Santiago: Ediciones Universidad Alberto Hurtado, 2013.

- “¿Una transformación metodológica inadvertida? La novedad introducida por Gaudium et spes en los escritos de Joseph Ratzinger". Teología y vida 57 (2016): 9-37.

Segundo, Juan Luis. "Libertad y liberación". En Mysterium liberationis. Conceptos fundamentales de la teología de la liberación, por Ignacio Ellacuría y Jon Sobrino, Vol. 1, 373-392. Madrid: Trotta, 1990.

. Teología de la liberación. Respuesta al cardenal Ratzinger. Madrid: Cristiandad, 1985.

Sobrino, Jon. "Centralidad del reino de Dios en la teología de la liberación". En Mysterium liberationis. Conceptos fundamentales de la teología de la liberación, por Ignacio Ellacuría y Jon Sobrino, Vol. 1, 467-510. Madrid: Trotta, 1990.

. Jesucristo liberador. Lectura histórico-teológica de Jesús de Nazaret. Madrid: Trotta, 1991.

- "La Iglesia de los pobres no prosperó en el Vaticano II. Promovida en Medellín, historizó elementos esenciales en el Concilio". Centro de Estudios y Publicaciones 37/228 (2012): 24-33.

. "Teología en un mundo sufriente. La teología de la liberación como intellectus amoris". Revista latinoamericana de teología 5 (1988): 243-266.

Tepedino, Ana María. Las discípulas de Jesús. Madrid: Narcea, 1994.

Tomichá, Roberto. "Aportes de los pueblos indígenas a la iglesia y a la teología hoy". CLAR 50/4 (2012): 96-105.

Trigo, Pedro. "El método teológico". En ITER, XXX años de itinerancia, por Varios autores, 135-230. Caracas: ITER-UCAB, 2010. 
Valiente, Ernesto. "The Reception of the Vatican II in Latin America”. Theological Studies 73 (2012): 795-823.

Vélez, Consuelo. El método teológico. Fundamentos, especializaciones, enfoques. Bogotá: Pontificia Universidad Javeriana, 2008. . "Teología de la mujer, feminismo y género". Theologica Xaveriana 140 (2001): 545-564.

___ "Teología feminista latinoamericana de la liberación: balance y futuro". Horizonte 11/32 (2013): 1801-1812. 